\title{
nature
}

\section{South Africa's new landscape}

Despite progress towards racial integration, proposals to rationalize by merging universities are being attacked as threats to the identity of some institutions. There is another way forward that deserves to be considered.

$t$ is ironic that current plans to restructure South Africa's highereducation system - including the merger of many of the country's historically black institutions with historically white ones — are being met with so much resistance from the very institutions that serve to benefit most from the changes. But South Africa's education minister, Kader Asmal, has made it clear that, after many years of procrastination on this issue, the country should no longer be held to ransom by vested interests in the face of declining registrations at many of its universities.

Most of South Africa's historically white institutions have made significant progress in becoming nonracial, to the extent that they now have more black students than the country's historically black ones (see page 377 ). The challenge is to find the best way of extending this process to upgrading the historically black universities and technikons (polytechnics), most of which were set up during the apartheid era to cater for specific ethnic groups.

The plan currently under consideration by the South African cabinet, drawn up by the National Working Group on higher education, is to merge all but seven of the country's 21 universities and 15 technikons into 21 institutions. Twelve of the proposed 14 new institutions would involve mergers between historically black and historically white ones; the other two would be between historically black institutions.

This proposal might be workable if effective new management procedures are put in place, and could certainly promote broader access to the better resources of the historically white institutions. But it is questionable whether the proposed four new 'comprehensive institutions', which would offer both university and technikon programmes, could really work within the context of a system that retains a distinction between the two.

Two years ago, another higher-education government taskforce proposed an alternative set of reform plans. It suggested dividing the country's universities and technikons into three categories: those that could award degrees up to doctoral level in all fields, those that could award only up to masters degrees in certain fields, and those that could award only undergraduate degrees.

Historically black institutions feared that they might fall into the last category, and their objections killed the proposals. But as problems with the latest plans are being aired, the previous model is once again being debated - if not by the cabinet, then at least within the universities themselves. The alternative model would at least allow institutions to retain their own identity — something they seem to be fearful of losing.

In addition, it would have the advantage of retaining undergraduate universities, at least, within reasonable access of the rural communities that several of them serve. Staff at these institutions could develop collaborative research programmes with established research universities, in a similar manner to the way that college staff do in the United States. If this were to happen, then researchers at these universities need not be denied the opportunity to continue with research, even if their universities were designated as undergraduate colleges. Many workable collaborations already exist between historicallyblack and historically white universities in South Africa - both for teaching and research purposes - so in many instances there is a sound basis on which to expand.

Whichever model is adopted, the rationalization of the South African higher-education system will have implications for funding agencies, both within and outside the country. There is little point in research funds being directed at institutions that lack a research culture and are unlikely to acquire one. A new dispensation should precipitate increased international funds for research. It should also ensure that funds are better deployed.

\section{Nature and the developing world}

Nature's publishers are making their journals freely available to the world's poorest countries.

A $\mathrm{t}$ the beginning of this year, a report from the World Health Organization (WHO) highlighted the potential benefits for the developed world in giving more aid to developing countries. The scale of increased aid that was recommended was big, according to economist Jeffrey Sachs and his committee, but so were the potential benefits (see Nature 415, 1; 2002).

Making scientific and medical journals available cheaply or at zero cost was just one component of Sachs' wish-list. To its credit, the WHO was able to begin to fulfil that hope with a scheme that it launched in January, ponderously entitled the Health Internetwork Access to Research Initiative (HINARI). In this scheme, publishers collaborate with the WHO's Health Internetwork (see www.healthinternetwork.net), which acts as an online gateway and validator for libraries, 490 of which have been identified by the WHO. Publishers make their information freely available from their own resources, without payment from third parties.
At present, free access through HINARI is provided to most of the 106 countries that fall below a threshold of having an annual gross national product per head of US $\$ 1,000$. From next year it is intended that journals will also be available at greatly reduced prices to the 39 countries whose gross national product per head falls between $\$ 1,000$ and $\$ 3,000$.

From 24 May, Nature and all other journals published by the Nature Publishing Group will become available through the HINARI scheme. That, coupled with the SciDev.Net free-access website that was spun off from Nature last year (see www.scidev.net), is one step towards the goals outlined by Sachs' committee.

In practice, the HINARI scheme has encountered some teething difficulties but, according to those in charge, it now works effectively. The biggest obstacle to access, they say, comes from "poor and extremely expensive connectivity”. Telecommunication providers and governments, please note. 